\title{
Evaluating the impacts of stressors of Pseudomonas syringae pathovar tomato on the effectiveness of multi-locus variable number tandem repeat analysis and multi-locus sequence typing in microbial forensic investigations
}

\author{
Mindy James ${ }^{1 *}$, Ulrich Melcher ${ }^{2}$ and Jacqueline Fletcher ${ }^{1}$
}

\begin{abstract}
Background: Crops in the USA are vulnerable to natural and criminal threats because of their widespread cultivation and lack of surveillance, and because of implementation of growing practices such as monoculture. To prepare for investigation and attribution of such events, forensic assays, including determination of molecular profiles, are being adapted for use with plant pathogens. The use of multi-locus variable number tandem repeat (VNTR) analysis (MLVA) and multi-locus sequence typing (MLST) in investigations involving plant pathogens may be problematic because the long lag periods between pathogen introduction and discovery of associated disease may provide enough time for evolution to occur in the regions of the genome employed in each assay. Thus, more information on the stability of the loci employed in these methods is needed.

Results: The MLVA fingerprints and MLST profiles were consistent throughout the experiment, indicating that, using a specific set of primers and conditions, MLVA and MLST typing systems reliably identify P.S. tomato DC3000. This information is essential to forensic investigators in interpreting comparisons between MLVA and MLST typing profiles observed in P.s. tomato isolates.

Conclusions: Our results indicate that MLVA and MLST typing systems, utilizing the specified primers and conditions, could be employed successfully in forensics investigations involving P.s. tomato. Similar experiments should be conducted in the field and with other high-consequence plant pathogens to ensure that the assays are reliable for pathogens infecting plants in their natural environment and for organisms that may display faster rates of mutation.
\end{abstract}

Keywords: Forensic microbiology, Agricultural biosecurity, Multi-locus variable number tandem repeat analysis, Multi-locus sequence typing, Pseduomonas syringae pathovar tomato, Bacterial evolution

\section{Background}

The American agricultural system is vulnerable to attack by bioterrorists or other criminals in several food-related areas such as production, processing and distribution [1]. Factors increasing the vulnerability of the cropping systems in the US to such attacks include their scattered nature, lack of surveillance, and considerable monoculturing [2].

\footnotetext{
* Correspondence: mindymc@okstate.edu

'Department of Entomology and Plant Pathology, Oklahoma State University, Stillwater 74078, OK, USA

Full list of author information is available at the end of the article
}

To prepare for the investigation of possible biological crimes on US agriculture, traditional forensic science techniques are being adapted for use with plant pathogens and other environmental samples that may be associated with agricultural environments [3]. To attribute an agroterrorism or criminal event to a perpetrator, a microbial forensics laboratory often determines a microbial signature or fingerprint for the organism of interest $[4,5]$. Methods used commonly to fingerprint pathogens, differentiate between microbial strains, and determine microbial relatedness include multi-locus variable number 
tandem repeat (VNTR) analysis (MLVA) and multi-locus sequence typing (MLST) [4].

VNTRs are short, tandemly repeated genomic sequences, present in the majority of prokaryotic and eukaryotic organisms, which vary in repeat copy number between strains of a single microbial species [6]. Variation in VNTR copy number is often exploited for strain differentiation using MLVA [5]. MLVA typing involves PCR amplification of multiple VNTR loci, followed by electrophoretic separation of the resulting fragments. Variation in the number of repeats at a particular locus results in the production of amplicons of different sizes, creating a VNTR fingerprint for the bacterial strain of interest $[7,4]$. The fingerprint is then used as a confirmation of microbial species identity. Additionally, hypervariability at a given VNTR locus, which can be used to indicate that different bacterial isolates originated from a common source, may be especially useful for the purposes of attribution [5,8].

MLVA has been used to successfully fingerprint a variety of bacteria, including Bacillus anthracis, Escherichia coli O157, Brucella abortus, and the plant pathogens Xylella fastidiosa, Xanthomonas oryzae, and Pseudomonas syringae [9-12]. However, because MLVA relies on genetic loci having intrinsically high mutation rates [9], VNTR loci can be affected by treatments such as environmental stress and serial passaging, leading to alteration in the MLVA fingerprints of organisms of interest $[9,13,14]$. For this reason, a better understanding of the stability and mutational rates of VNTR loci is needed to permit the interpretation of MLVA results in forensic investigations $[15,7]$.

Forensic investigators may need to identify a suspect microorganism to the strain level. MLST allows for strain-level microbe identification by comparing the sequences of multiple genomic housekeeping genes required for normal functioning of the organism [16,17]. In this method, PCR is used to amplify 450 to $500 \mathrm{bp}$ length fragments of 5 to 10 housekeeping genes. The amplicons are then sequenced and compared with the profiles of isolates stored in searchable databases [16].

MLST has been used effectively to characterize a variety of bacterial species, and has been successfully employed in studies of bacterial recombination and genetic diversity $[4,18]$. A highly reproducible method, it can be adapted easily to any set of genes by designing specific primers $[16,19]$. The major strength of MLST lies in its ability to detect recombination; however, the technique does not always provide reliable differentiation of strains from recently evolved bacterial species that display little genetic variability $[18,20,17]$.

The use of common forensic assays, such as MLVA and MLST, may be especially problematic in forensic investigations involving plant pathogens because the long lag periods between the introduction of a pathogen and the discovery of the subsequent disease may provide ample time for the pathogen to undergo evolution in regions of the genome used in the microbe-typing assays [2,21].

Pseudomonas syringe pv. tomato, used as a model organism by many investigators, is a Gram negative, plant pathogenic bacterium with a worldwide distribution [22,23]. The pathogen infects Arabidopsis thaliana, Brassica species, and tomato, in the latter of which it causes bacterial speck disease, an economically important disease $[24,25]$. P.s. tomato was chosen for this work because of the availability of several genome sequences and because it meets several criteria for potential bioweapons, including ease of handling, toxin production, rate of infection and spread in nature, and yield losses associated with infection [26].

MLVA and MLST have both been employed by others in the study of P.s. tomato. A P.s. tomato MLVA assay was developed for rapid strain discrimination and for determining phylogenetic relationships between strains [12]. These and other studies using MLVA to examine the relatedness of P.s. tomato strains revealed that the diversity within the pathogen is highly correlated with the host plant species in which the organism lived $[12,27]$. Similarly, MLST has been used to investigate the genetic stability of $P$. syringae (multiple pathovars) and to resolve the role of recombination in the evolution of the pathogen. Strains of P. syringae remained genetically consistent over long periods, indicating that the species is highly clonal [18]. However, using MLST, researchers were able to identify multiple recombination sites within the P.s. tomato genome, indicating that recombination contributed greatly to the genetic variation of the organism [28].

In the present study, we examined the ability of MLVA and MLST typing methods to type P.s. tomato that was subjected to various treatments, in order to evaluate the appropriateness of their use in microbial forensic investigations involving plant pathogens.

\section{Methods}

\section{Bacterial strain and experimental treatments}

P.s. tomato DC3000, originally isolated from infected tomatoes in the Channel Islands, Guernsey, UK, was obtained from the laboratory of Dr Carol Bender, previously of Oklahoma State University. Prior to beginning the experiment, the bacterium was grown in King's B broth medium under optimum conditions reported for this organism $\left(28^{\circ} \mathrm{C}\right.$ with shaking at $\left.150 \mathrm{rpm}\right)$ [29]. This master culture was used in preparation of experimental treatments.

P.s. tomato DC3000 was exposed to four treatments, meant to simulate various environmental conditions to which it could be exposed before or during a biological 
attack, while the bacterium was being sequentially sub-cultured for 1 year to mimic continued growth of the pathogen in the field. Treatments comprised: 1) P.s. tomato $\mathrm{DC} 3000$ grown under optimum laboratory conditions, 2) P.s. tomato DC3000 grown under suboptimal conditions (nutritional stress), 3) mutagenesis of P.s. tomato DC3000 followed by growth under optimum conditions, and 4) P.s. tomato DC3000 grown in planta. Optimal growth conditions were provided by growth of the bacterium under optimized laboratory conditions [30]. Growth of the organism in nature was simulated by growing it in sub-optimal medium and in planta. Mutagenesis of P.s. tomato DC3000 was used to discern the effects, if any, of enhanced evolutionary rates on the reliability of the forensic assays.

For treatment 1 (optimum conditions), $40 \mathrm{ml}$ of King's B (KB) broth was inoculated with $0.1 \mathrm{ml}$ of the P.s. tomato master culture and incubated at $28^{\circ} \mathrm{C}$ with shaking at $150 \mathrm{rpm}$ for 4 days. On day 3 of incubation, $10 \mathrm{ml}$ of the culture was removed, and total genomic DNA was extracted using the Qiagen DNeasy Blood and Tissue Kit in accordance with the manufacturer's instructions (Qiagen, Valencia, CA, USA). On day 4 of incubation, the remaining culture was used to inoculate fresh King's B broth as above. This process was repeated every 4 days for 1 year.

For treatment 2 (sub-optimal conditions), $40 \mathrm{ml}$ of mannitol-glutamate broth, a minimal medium, was inoculated with $0.1 \mathrm{ml}$ of the master culture [31]. The culture was incubated at $28^{\circ} \mathrm{C}$ with shaking as for treatment 1 , and DNA extraction and further sub-culturing was carried out as described above.

Mutagenesis was carried out on $10 \mathrm{ml}$ of the P.s. tomato master culture using ethyl methanesulfonate (EMS), a chemical that generates mutations by guanine alkylation, following the method described by Thomas and Leary with slight modifications [32,33]. For this, $10 \mathrm{ml}$ of log phase bacteria, in King's B broth, were exposed to EMS $(1 \mathrm{mg} / \mathrm{ml}$ of broth) for 4 hours. This culture was diluted 1:20 in fresh medium and incubated at $28^{\circ} \mathrm{C}$ with shaking at $150 \mathrm{rpm}$ for 24 hours. The bacterial cells were washed by centrifugation and resuspended in fresh King's B broth [33], then $40 \mathrm{ml}$ of King's B broth were inoculated with $0.1 \mathrm{ml}$ of the culture. The culture was incubated at $28^{\circ} \mathrm{C}$ with shaking as with treatments 1 and 2, and DNA extraction and subculturing were carried out as described above.

For the in planta treatment, 3-week-old tomato (Lycopersicum esculentum cv. Glamour) seedlings were inoculated with the master culture of P.s. tomato by dipping a sterile swab into a 4-day culture and lightly rubbing the undersides of 3 to 5 expanded leaves. The inoculated plants were maintained in a growth chamber at $25^{\circ} \mathrm{C}$ with $50 \%$ relative humidity and a 12 -hour photoperiod. One month after inoculation, leaf tissue was excised from the lesion margins and soaked in $1 \mathrm{ml}$ of sterile water for 3 hours. The resulting suspension was then streaked for isolation on King's B agar plates, which were incubated at $28^{\circ} \mathrm{C}$. When bacterial colonies were obvious, plates were examined using ultraviolet light for the presence of fluorescent colonies typical of P.s. tomato grown on this medium [34]. Several fluorescent colonies were transferred to $10 \mathrm{ml}$ of $\mathrm{KB}$ broth and incubated at $28^{\circ} \mathrm{C}$ with shaking at $150 \mathrm{rpm}$ for 24 hours. That bacterial suspension was used to inoculate new tomato seedlings as described above, and the remaining culture was used for DNA extraction as previously described. For this treatment, the P.s. tomato culture was transferred seven times over a 10 -month period.

DNA samples extracted from liquid cultures at 6-week intervals, and from each culture transfer in planta, were subjected to molecular analysis using MLVA and MLST.

\section{Multi-locus variable number tandem repeat analysis}

MLVA analysis of VNTR regions within the P.s. tomato genome was carried out using previously described VNTR loci (Table 1), primer pairs (Table 2) and molecular methods [12]. PCR amplification of VNTR loci were performed as singleplex reactions using locus-specific PCR primers (Table 2), GoTaq Flexi DNA Polymerase with accompanying reagents (Promega, Madison, WI, USA), and PCR Nucleotide Mix (Fisher Bioreagents, Pittsburg, PA, USA) in a final reaction volume of $25 \mu$ l. Cycling conditions were as follows: 2 minutes at $95^{\circ} \mathrm{C}$, followed by 30 cycles of 1 minute at $94^{\circ} \mathrm{C}, 1$ minute at $55^{\circ} \mathrm{C}$, and 1 minute at $72^{\circ} \mathrm{C}$, with a final extension step at $72^{\circ} \mathrm{C}$ for 7 minutes.

Following amplification, the MLVA fingerprint for each sample was visualized by gel electrophoresis using a $1.5 \%$ agarose gel supplemented with $0.1 \mu \mathrm{l} / \mathrm{ml}$ of SyBR ${ }^{\circ}$ Safe DNA Gel Stain (Invitrogen, Carlsbad, CA, USA). To ensure that electrophoresis could adequately distinguish between the amplicon sizes, MLVA was also performed on a separate P.s. tomato strain, P.s. tomato 1318, having different numbers of repeats from P.s. tomato DC3000 at three of the chosen VNTR loci: P.s. tomato

\begin{tabular}{|c|c|c|}
\hline VNTR locus & Motif length, bp & Repeats in Pst DC3000, $n$ \\
\hline 715 & 7 & 7.3 \\
\hline 1570 & 6 & 13.5 \\
\hline 1929 & 144 & 1.9 \\
\hline 337 & 125 & 2.9 \\
\hline 919 & 829 & 2.0 \\
\hline
\end{tabular}

MLVA, Multi-locus variable number tandem repeat analysis; VNTR, Variable number tandem repeat.

${ }^{\mathrm{a}}$ From: Baker [12]. 
Table 2 VNTR primers used in MLVA typing of Pseudomonas syringae pathovar tomato DC3000

\begin{tabular}{llll}
\hline $\begin{array}{l}\text { VNTR locus } \\
\text { primer }^{\mathbf{a}}\end{array}$ & Direction & Primer sequence $\mathbf{( 5}^{\prime} \boldsymbol{\rightarrow} \mathbf{3}^{\prime} \mathbf{)}$ & $\begin{array}{l}\text { Product } \\
\text { size, bp }\end{array}$ \\
\hline 715-F & Forward & TGTGCGATGACACGCTTACCCATA & 314 \\
715-R & Reverse & TATTCGCGGACATTCGTGACAAGA & \\
1570-F & Forward & AGTCTCTGCTCTTGGTGGCGTA & 216 \\
1570-R & Reverse & GTCTGATGTACATGGTGCGCTGGT & \\
1929-F & Forward & CGAACAGAACGCGGCCTTCAAATA & 511 \\
1929-R & Reverse & ACAGCGACTGAGCTGATTCAGGAT & \\
337-F & Forward & TGGAGCACAAACTGCTCTGAGTCT & 440 \\
337-R & Reverse & TACAGAGATGGCGCGATTGAGCA & \\
919/920-F & Forward & AAACATCAGCCAGCAAATCACCCG & 829 \\
919/920-R & Reverse & AACTGTTATGCCTTGTCGCACAGC & \\
\hline
\end{tabular}

MLVA, Multi-locus variable number tandem repeat analysis; VNTR, Variable number tandem repeat.

a'From: Baker [12].

1318 has one fewer repeat at loci 715 and 1929, and four additional repeats at locus 337 than P.s. tomato DC3000. A 100 bp DNA ladder (Invitrogen) was used with all gels. The sizes of the resulting amplicons were representative of the number of repeats at each locus in P.s. tomato 1318, and could be distinguished easily from those in P.s. tomato DC3000, based on size (Figure 1).

\section{Multi-locus sequence typing}

MLST analysis of the P.s. tomato genome was carried out using previously published genes, primers, and molecular methods $[18,35]$. The core genome components evaluated encode for glyceraldehyde-3-phosphate dehydrogenase $($ gapA), phosphofructokinase ( $p f k)$, sigma factor 70 (rpoD),

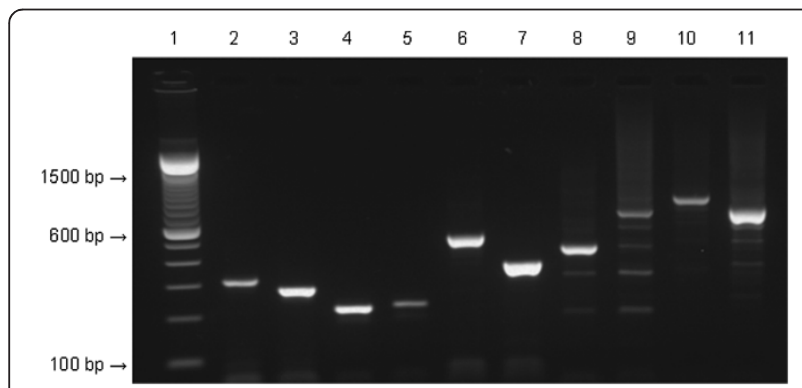

Figure 1 Size comparison of amplicons resulting from PCR amplification with locus-specific primers used in Pseudomonas syringae pathovar tomato DC3000 multi-locus variable number tandem repeat analysis (MLVA) typing assay. Lane 1, $100 \mathrm{bp}$ DNA ladder; lane 2, locus 715 of P.s. tomato DC3000; lane 3, locus 715 of P.s. tomato 1318; lane 4, locus 1570 of P.s. tomato DC3000; lane 5, locus 1570 of P.s. tomato 1318; lane 6, locus 1929 of P.S. tomato DC3000; lane 7, locus 1929 of P.s. tomato 1318; lane 8, locus 337 of P.s. tomato DC3000; lane 9, locus 337 of P s. tomato 1318; lane 10, locus 919 of P.s. tomato DC3000; lane 11, locus 919 of P.s. tomato 1318. aconitate hydratase B $(a c n B)$, phosphoglucoisomerase (pgi), gyrase $($ gyrB), and citrate synthase $(c t s)$.

PCR amplification of each gene was carried out on 10 ng of template DNA using gene-specific PCR primers (Table 3), GoTaq Flexi DNA Polymerase and accompanying reagents (Promega, Madison, WI), and PCR Nucleotide Mix (Fisher Bioreagents, Pittsburg, PA) in a final reaction volume of $25 \mu \mathrm{l}$. Cycling conditions were as follows: 2 minutes at $94^{\circ} \mathrm{C}$, followed by 30 cycles of 1 minute at the appropriate annealing temperature (Table 4), and 1 minute at $72^{\circ} \mathrm{C}$. Following this initial PCR reaction, the PCR products were cleaned using ExoSAP-IT PCR cleanup reagent (Affymetrix, Santa Clara, CA, USA) in accordance with manufacturer's instructions. The clean products were then employed as template in a second amplification reaction as preparation for sequencing.

For the sequencing reaction, a master mix was prepared for each primer, consisting of $10 \mu \mathrm{l}$ sterile water, $3 \mu \mathrm{l} 5 \times$ Sequencing Buffer (BigDye Terminator

Table 3 Primers used in multi-locus sequence typing of Pseduomonas syringae pathovar tomato DC3000

\begin{tabular}{|c|c|c|}
\hline Primer $^{a}$ & Direction & Sequence $\left(5^{\prime} \rightarrow 3^{\prime}\right)$ \\
\hline $\mathrm{acn}-\mathrm{Fp}{ }^{\mathrm{b}}$ & Forward & ACATCCCGCTGCACGCYCTGGCC \\
\hline$a c n-R p^{b}$ & Reverse & GTGGTGTCCTGGGAACCGACGGTG \\
\hline $\mathrm{acn}-\mathrm{Fs} \mathrm{s}^{\mathrm{b}}$ & Forward & ATGAARCAGATMGAAGAAATGCGCGG \\
\hline$a c n-R s^{b}$ & Reverse & GCCRACCATCTTYTGCGCMAGGG \\
\hline $\mathrm{cts}-\mathrm{Fp} \mathrm{b}^{\mathrm{b}}$ & Forward & AGTTGATCATCGAGGGCGCWGCC \\
\hline cts-Rp ${ }^{b}$ & Reverse & TGATCGGTTTGATCTCGCACGG \\
\hline $\mathrm{cts}-\mathrm{Fs} \mathrm{s}^{\mathrm{b}}$ & Forward & CCCGTCGAGCTGCCAATWCTGA \\
\hline cts-Rs ${ }^{b}$ & Reverse & ATCTCGCACGGSGTRTTGAACATC \\
\hline gapA-Fps ${ }^{b}$ & Forward & CGCCATYCGCAACCCG \\
\hline gapA-Rps ${ }^{b}$ & Reverse & CCCAYTCGTTGTCGTACCA \\
\hline gyrB-Fps ${ }^{c}$ & Forward & MGGCGGYAAGTTCGATGACAAYTC \\
\hline gyrB-Rps ${ }^{c}$ & Reverse & TRATVKCAGTCARACCTTCRCGSGC \\
\hline$p f k-F p^{b}$ & Forward & ACCMTGAACCCKGCGCTGGA \\
\hline pfk-Rp & Reverse & ATRCCGAAVCCGAHCTGGGT \\
\hline $\mathrm{pfk}-\mathrm{Fs} \mathrm{s}^{\mathrm{b}}$ & Forward & AGCAAYATCAAGMTGGCCGA \\
\hline$p f k-R s^{b}$ & Reverse & ACCATGCCKGCCARMAGCG \\
\hline pgi-Fpp & Forward & TCAAGGACTTCAGCATGCGCGAAGC \\
\hline pgi-Rp ${ }^{b}$ & Reverse & CGAGCCGCCCTGSGCCAGGTACCAG \\
\hline pgi-Fs ${ }^{b}$ & Forward & TTCAGCATGCGCGAAGCG \\
\hline pgi-Rs ${ }^{b}$ & Reverse & TGCGCCAAGGTACCAGG \\
\hline $\mathrm{rpoD}-\mathrm{Fp}^{\mathrm{c}}$ & Forward & AAGGCGARATCGAAATCGCCAAGCG \\
\hline rpoD-Rps ${ }^{c}$ & Reverse & GGAACWKGCGCAGGAAGTCGGCACG \\
\hline rpoD-Fs ${ }^{b}$ & Forward & AAGCGAATCGAAGAAGGCATYCGTG \\
\hline
\end{tabular}

${ }_{\mathrm{p}} \mathrm{p}-\mathrm{PCR}$ primer, s-sequencing primer.

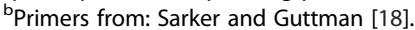

'Primers from: Sawada et al. [35]. 
Table 4 Pseduomonas syringae pathovar tomato DC3000 multi-locus sequence typing PCR primer annealing temperatures

\begin{tabular}{ll}
\hline PCR primer set & $\mathbf{T}_{\mathbf{a}}{ }^{\circ} \mathbf{C}^{\mathbf{a}}$ \\
\hline acn & 60 \\
cts & 56 \\
gapA & 62 \\
gyrB & 63 \\
pfk & 63 \\
pgi & 60 \\
rpoD & 63
\end{tabular}

${ }^{\mathrm{a}} \mathrm{T}_{\mathrm{a}}$, annealing temperature.

v1.1/3.1; Applied Biosystems Carlsbad, CA, USA), $2 \mu \mathrm{l}$ $10 \mathrm{mM}$ individual primer (Table 3), $2 \mu \mathrm{l}$ Ready Reaction Mix (BigDye v3.1; Applied Biosystems), and $2 \mu \mathrm{l}$ of cleaned PCR product from each sample. Cycling conditions were as follows: 30 seconds at $96^{\circ} \mathrm{C}$, followed by 26 cycles of 15 seconds at $50^{\circ} \mathrm{C}$, and 4 minutes at $60^{\circ} \mathrm{C}$. Prior to sequencing, ethanol precipitation was performed on each PCR product, then $12 \mu \mathrm{l}$ of sterile water, $5 \mu \mathrm{l} 3 \mathrm{M}$ ammonium acetate and $57 \mu \mathrm{l}$ of $100 \%$ ethanol were added to each sample, and mixed before centrifugation at $1,500 \mathrm{~g}$ for 30 minutes. After discarding the supernatant, $70 \mu \mathrm{l}$ of $70 \%$ ethanol was added to each sample, and tubes were centrifuged at $1,500 \mathrm{~g}$ for 15 minutes. The supernatant was discarded, $10 \mu \mathrm{l}$ of deionized water was added to the pellet, and tubes were mixed to suspend the DNA. The DNA was sequenced by the Oklahoma State University Recombinant DNA/Protein Core facility using a DNA analyzer (ABI Model 3730; Applied Biosystems). The resulting DNA sequences were aligned, trimmed, and analyzed using MEGA 4: Molecular Evolutionary Genetics Analysis software [36].

\section{Results}

Multi-locus variable number tandem repeat analysis

The MLVA typing system employed in this project utilized primers specific for five known VNTR loci within the P.s. tomato genome (Table 1). MLVA typing of the master P.s. tomato DC3000 culture used to inoculate the experimental treatments resulted in a baseline fingerprint for the organism (Figure 2), in which the amplicon size for each primer pair was as expected (Table 2). MLVA fingerprints obtained for sub-cultures 11, 22, 33, $44,55,66,77,88$, and 92 of non-mutagenized and mutagenized P.s. tomato DC3000 grown under optimal or sub-optimal conditions and P.s. tomato DC3000 from each plant passage were consistent with the baseline fingerprint of the organism, and did not appear to change over time. To ensure that no repeats were gained or lost

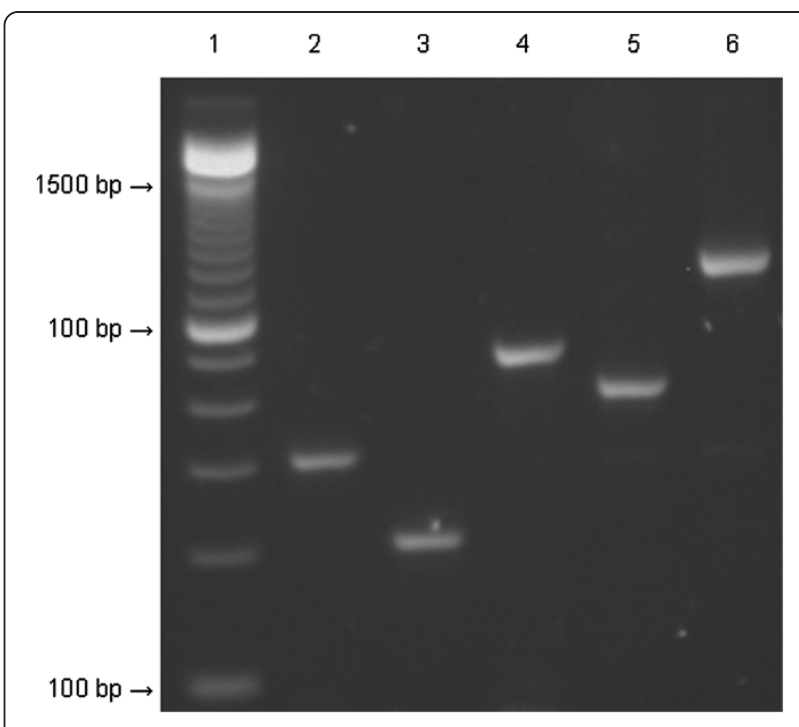

Figure 2 Representative multi-locus variable number tandem repeat analysis fingerprint for Pseudomonas syringae pathovar tomato DC3000. Lane 1, 100 bp DNA ladder; lane 2, locus 715; lane 3, locus 1570; lane 4, locus 1929; lane 5, locus 337; lane 6, locus 919.

over time, PCR products from amplification of each locus for all samples from each treatment were compared by gel electrophoresis. All bands for each locus were of the correct size (Table 2) and appeared to be, within the resolution of our analysis technique, indistinguishable for all samples (Figure 3, Figure 4).

\section{Multi-locus sequence typing}

A MLST typing system targeting seven core genome components of P.s. tomato was employed in this study (Table 3). Sequences for each gene were aligned and trimmed to a consistent length (Table 5). Analysis of the trimmed gene sequences from the master culture of P.s. tomato DC3000, sub-cultures 11, 22, 33, 44, 55, 66, 77, 88, and 92 of non-mutagenized and mutagenized P.s. tomato DC3000 grown under optimal or sub-optimal conditions, and P.s. tomato DC3000 from each plant passage revealed no mutations during the sampling period.

\section{Discussion}

Attribution of a biocrime or bioterror event involving a plant pathogen may require a forensics laboratory to determine a microbial fingerprint or profile for the organism $[4,5]$. Previous research has shown that VNTR loci may undergo mutation in response to serial passaging and environmental stressors such as increased temperature, starvation, and irradiation $[14,13]$. For example, E. coli O157:H7 grown with creek water as a sole nutrient source underwent triple and quadruple repeat changes within VNTR loci [13]. Similarly, B. abortus strain 544 was shown to gain a repeat in three observed 


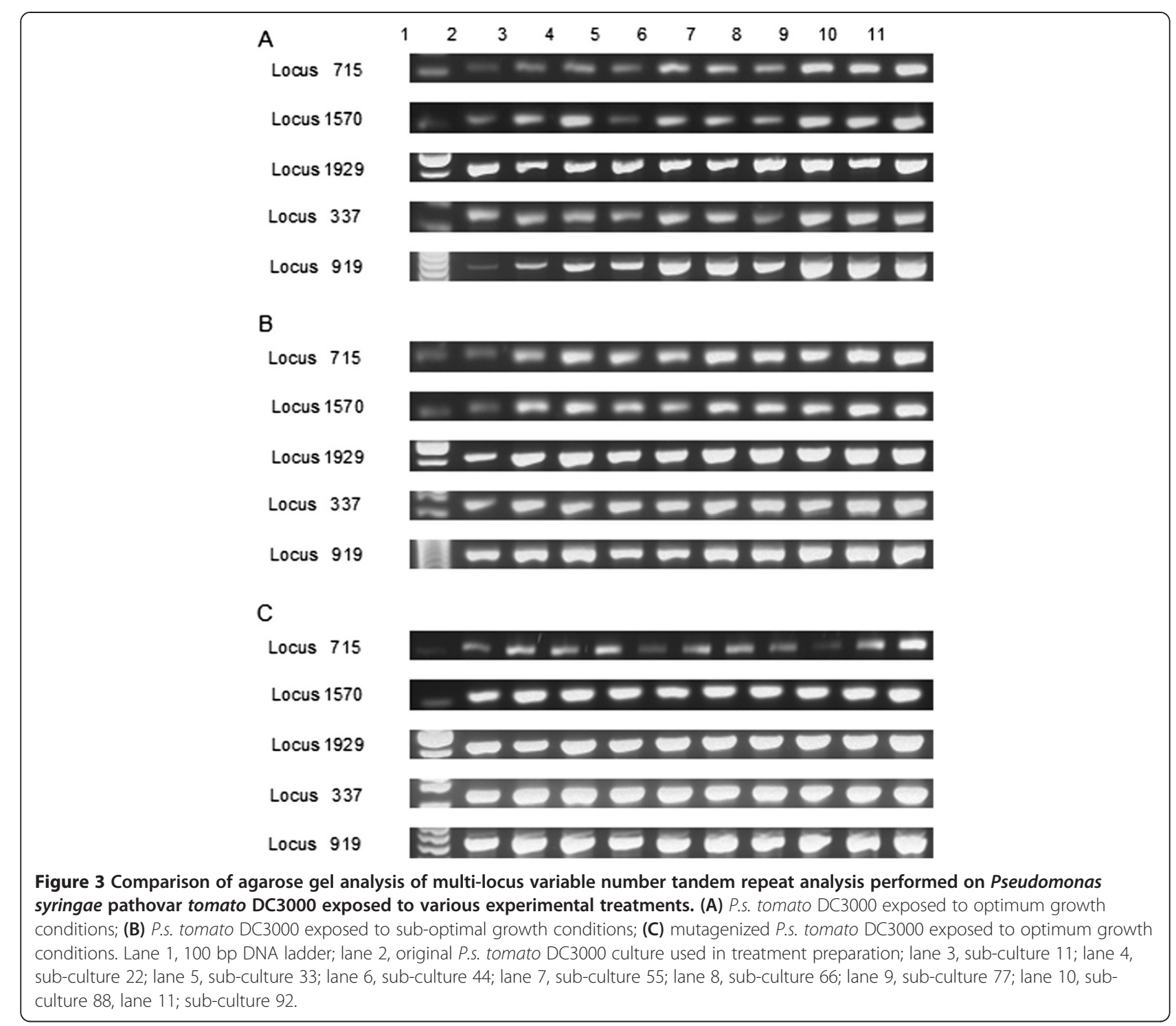

Locus 715
Locus 1570
Locus 1929
Locus 337
Locus 919
varigure 4 Compariable number tandem repeat analysis performed on
Pseudomonas syringae pathovar tomato DC3000 after passage
through tomato. Lane 1, 100 bp DNA ladder; lane 2, passage 1;
lane 3, passage 2; lane 4, passage 3; lane 5, passage 4; lane 6,
passage 5; lane 7, passage 6; lane 8, passage 7.

VNTR loci during serial passaging; however, three other strains of the pathogen showed no change [14]. In the current study, the MLVA fingerprint for P.s. tomato DC3000, generated using primers for five specific VNTR loci (Table 2), did not change over time, and was not affected by the experimental treatments. These results indicate that the VNTR regions employed in the Pst MLVA assay are stable within the genome and are not affected by culturing conditions, including growth in the plant host. Thus, the assay could reliably type the organism in an investigation involving the pathogen; however, similar experiments should be performed in the field to ensure that other adverse natural conditions will have 
Table 5 Trimmed sequence lengths for genes used in P.s. tomato MLST assay

\begin{tabular}{lll}
\hline Gene & Gene length, $\mathbf{b p}^{\mathbf{a}}$ & Trimmed sequence length, bp \\
\hline Acn & 399 & 477 \\
Cts & 445 & 478 \\
GapA & 497 & 625 \\
GyrB & 480 & 575 \\
Pfk & 414 & 619 \\
Pgi & 448 & 576 \\
RpoD & 452 & 546 \\
\hline
\end{tabular}

a From: Sarkar and Guttman [18].

no effect on the validity of the assay. These findings could also be of use for investigation of natural events and in epidemiological studies.

Our MLST results correspond with the previous findings that the core genome of $P$. syringae is highly clonal and displays very little genetic heterogeneity [18]. Each passage consisted of taking $0.1 \mathrm{ml}$ of culture into $40 \mathrm{ml}$ of medium and incubating for 4 days. This is a $400 \times$ increase in the number of cells per culture period, or approximately 10 generations per sub-culture. With a total length of $2.3 \mathrm{kbp}$ for the MLST products and an expectation of $1 \times 10^{-8}$ substitutions/bp/generation, we would anticipate approximately 0.023 substitutions. By observing nearly 100 samples per experiment and including a treatment that should have dramatically increased the mutation rate, we expected to see a change in the target sequences. However, the nucleotide sequences of the seven housekeeping genes employed in the P.s. tomato MLST assay did not change over time, and were not affected by the experimental treatments, indicating that MLST could also be employed successfully in an investigation involving the pathogen. As MLST typing systems are particularly useful for detection of recombination, the results of the P.s. tomato MLST assay could be affected by the presence of other microorganisms during growth of the pathogen $[18,20,28]$. To further ensure the validity of the assay, similar experiments should be performed in the field under natural environmental conditions and in the presence of a variety of other microbes.

The MLVA and MLST assays employed in this experiment did not reveal any differences in the DNA sequences assessed, based on the various culturing conditions tested. We were somewhat surprised at this result, as a variety of treatments were continued for a full year; however, selection of different VNTR loci or housekeeping genes might reveal changes (not observed in our work) within the P.s. tomato DC3000 genome. In a follow-up, collaborative study currently underway, whole genome sequencing of these strains will provide a more comprehensive view of genetic changes in these and other strains of P.s. tomato.
The fact that, in our experiment, both MLVA and MLST typing systems were effective for characterization of P.s. tomato in microbial forensic investigations does not mean that all phytopathogenic bacterial species will have similarly low mutation rates. Plant pathogens belong to a variety of taxonomic kingdoms and genera, and infect various plant hosts in many different environments, and it is likely that these factors will influence the specific mutation rate of each organism. Experiments similar to those conducted here should be carried out with other important plant pathogens to ensure the validity of MLVA and MLST typing systems for those organisms. In new pathogens, whole genome sequencing could be employed to identify stable VNTR loci and housekeeping genes within the genome that could be employed in development of MLVA and MLST assays for the pathogen of interest.

\section{Conclusions}

The results of this study indicate that MLVA and MLST typing systems, utilizing the specified primers and conditions, could be employed successfully in forensic investigations involving P.s. tomato. However, similar experiments should be conducted in the field and with high-consequence plant pathogens to ensure that the assays are reliable for organisms infecting plants in nature, and for use with other plant pathogens that may display faster rates of mutation than P.s. tomato.

\section{Abbreviations}

EMS: Ethyl methanesulfonate; MEGA: Molecular Evolutionary Genetics Analysis; mIMLST: Multi-locus sequence typing; MLVA: Multilocus variable number tandem repeat analysis; $p v$ : Pathovar; $T_{a}$ : Annealing temperature; VNTR: Variable number tandem repeat.

\section{Competing interests}

The authors declare that they have no competing interests.

\section{Authors' contributions}

$\mathrm{MJ}$ participated in the design of the study and carried out the experimental design, bacterial typing, data analysis, and drafted the manuscript. UM conceived of the study, participated in the design of the study and data analysis, and was involved in drafting of the manuscript. JF participated in design of the study and data analysis, and was involved in drafting of the manuscript. All authors read and approved the final version of the manuscript.

\section{Acknowledgements}

We thank Carol Bender, previously of Oklahoma State University, for supplying the original culture of P.s. tomato DC3000. This work was approved for publication by the Director of the Oklahoma Agricultural Experiment Station and supported in part under project OKL 2052.

\section{Author details}

${ }^{1}$ Department of Entomology and Plant Pathology, Oklahoma State University, Stillwater 74078, OK, USA. ${ }^{2}$ Department of Biochemistry and Molecular Biology, Oklahoma State University, Stillwater 74078, OK, USA.

Received: 23 April 2014 Accepted: 14 July 2014

Published: 7 August 2014 


\section{References}

1. Harl NE: U.S. Agriculture, food production is threatened by bioterrorism attacks. http://www.econ.iastate.edu/faculty/harl/USAgThreatened.pdf.

2. Madden LV, Wheelis M: The threat of plant pathogens as weapons against U.S. crops. Ann Rev Phytopath 2003, 41:155-176.

3. Fletcher J, Bender C, Budowle B, Cobb WT, Gold SE, Ishimaru CA, Luster D, Melcher U, Murch R, Scherm H, Seem RC, Sherwood JL, Sobral BW, Tolin SA: Plant pathogen forensics: capabilities, needs, and recommendations. Microbiol Mol Biol Rev 2006, 70:450-471.

4. Budowle B, Johnson MD, Fraser CM, Leighton TJ, Murch RS, Chakraborty R: Genetic analysis and attribution of microbial forensics evidence. Crit Rev Microbiol 2005, 31:233-254

5. Pattnaik P, Jana AM: Microbial forensics: applications in bioterrorism. Environ Forensics 2005, 6:197-204.

6. van Belkum A, Tassios PT, Dijkshoorn L, Haeggman S, Cookson B, Fry NK, Fussing V, Green J, Feil E, Gerner-Smidt P: Guidelines for the validation and application of typing methods for use in bacterial epidemiology. Clin Microbiol Infec 2007, 13(Suppl 3):1-46.

7. Vogler AJ, Keys C, Nemoto Y, Colman RE, Jay Z, Keim P: Effect of repeat copy number on variable-number tandem repeat mutations in Escherichia coli 0157:H7. J Bacteriol 2006, 188:4253-4263.

8. Keim P: Bacterial Pathogens. In Microbial Forensics. Edited by Breeze RG, Budowle B, Schutzer SE. Burlington, MA: Elsevier Academic Press; 2005:99-170.

9. Lindstedt B: Multiple-locus variable number tandem repeats analysis for genetic fingerprinting of pathogenic bacteria. Electrophoresis 2005, 26:2567-2582

10. Le Fléche P, Jacques I, Grayon M, Al Dahouk S, Bouchon P, Denoeud F, Nöckler K, Neubaruer H, Guilloteau LA, Vergnaud G: Evaluation and selection of tandem repeat loci for Brucella MLVA typing assay. BMC Microbiol 2006, 6:9.

11. Zhao A, Poulin L, Rodriguez-R LM, Serna NF, Liu S, Wonni I, Szurek B, Verdier V, Leach JE, He Y, Feng J, Koebnik R: Development of variable number of tandem repeats typing scheme for the bacterial rice pathogen Xanthomonas oryzae pv. oryzicola. Phytopath 2012, 102:948-956.

12. Baker C: Strain Typing and Characterization of Sigma54-Dependent Transcriptional Activator Mutants in Pseudomonas Syringae pv. Tomato, PhD Thesis. Oklahoma State University: Department of Entomology and Plant Pathology; 2009.

13. Cooley MB, Carychao D, Nguyen K, Whitehand L, Mandrell R: Effects of environmental stress on stability of tandem repeats in Escherichia coli O157:H7. Appl Environ Microbiol 2010, 76:3398-3400.

14. Her M, Kang S, Cho D, Cho Y, Hwang I, Heo Y, Jung S, Yoo H: Application and evaluation of the MLVA typing assay for the Brucella abortus strains isolated in Korea. BMC Microbiol 2009, 9:230

15. Hopkins KL, Maguire C, Best E, Liebana E, Threlfall EJ: Stability of multiplelocus variable number tandem repeats in Salmonella enterica serovar Typhimurium. J Clin Microbiol 2007, 45:3058-3061.

16. Cook CL Jr: Forensic genetic analysis of microorganisms: overview of some important technical concepts and selected genetic typing methods. In Microbial Forensics. Edited by Breeze RG, Budowle B, Schutzer SE. Burlington, MA: Elsevier Academic Press; 2005:233-249.

17. Keim P, Pearson T, Okinaka R: Microbial forensics: DNA fingerprinting of Bacillus anthracis (anthrax). Anal Chem 2008, 80:4791-4800.

18. Sarker SR, Guttman DS: Evolutiion of the core genome of Pseudomonas syringae, a highly clonal, endemic plant pathogen. Appl Environ Microbiol 2004, 70:1999-2012.

19. Maiden MCJ, Bygraves JA, Feil E, Morelli G, Russell JE, Urwin R, Zhang Q, Zhao J, Zurth K, Caugant DA, Feavers IM, Achtman M, Spratt BG: Multilocus sequence typing: a portable approach to the identification of clones within populations of pathogenic microorganisms. Proc Natl Acad Sci U S A 1998, 95:3140-3145.

20. Feil EJ, Maiden MC, Achtman M, Spratt BG: The relative contributions of recombination and mutation to the divergence of clones of Neisseria meningitides. Mol Biol Evol 1999, 16:1496-1502.

21. Nutter FW, Madden LV: Plant pathogens as biological weapons against agriculture. In Beyond Anthrax: The Weaponization of Infectious Diseases. Edited by Lutwick LI, Lutwick SM. New York: Humana Press; 2009:335-363.

22. Doudoroff M, Palleroni NJ: Genus I: Pseudomonas migula. In Bergey's Manual of Determinative Bacteriology. 8th edition. Edited by Buchanan RE, Gibbons NE. Baltimore, MD: Williams \& Watkins; 1974:217-243.
23. Kokalis-Burella N: 2002. In Biological Control of Crop Diseases. Edited by Gnanamanickam SS. New York: Marcel Dekker, Inc; 2002:179-190.

24. Lin N, Abramovitch RB, Kim YJ, Martin GB: Diverse AvrPtoB homologs from several Pseudomonas syringae pathovars elicit Pto-dependent resistance and have similar virulence activities. Appl Environ Microbiol 2006, 72:702-712.

25. Zhao Y, Damicone JP, Demezas DH, Rangaswamy V, Bender CL: Bacterial leaf spot of leafy crucifers in Oklahoma caused by Pseudomonas syringae pv. maculicola. Plant Dis 2000, 84:1015-1020.

26. Schaad NW, Shaw JJ, Vidaver A, Leach J, Erlick BJ: Crop biosecurity. http:// www.apsnet.org/publications/apsnetfeatures/Pages/CropBiosecurity.aspx.

27. Gironde S, Manceau C: Housekeeping gene sequencing and multilocus variable-number tandem-repeat analysis to identify subpopulations with Pseudomonas syringae pv. maculicola and Pseudomonas syringae pv. tomato that correlated with host specificity. Appl Environ Microbiol 2012, 78:3266-3279

28. Yan S, Liu H, Mohr TJ, Jenrette J, Chiodini R, Zaccardelli M, Setubal JC, Vinatzer BA: Role of recombination in the evolution of the model plant pathogen Pseudomonas syringae pv. tomato DC3000, a very atypical tomato strain. Appl Environ Microbiol 2008, 74:3171-3181.

29. King EO, Wark MK, Raney DE: Two simple media for the demonstration of pyocyanin and fluorescin. J Lab Clin Med 1954, 44:301-307.

30. Budde IP, Rohde BH, Bender CL, Ullrich MS: Growth phase and temperature influence promoter activity, transcript abundance, and protein stability during biosynthesis of the Pseudomonas syringae phytotoxin coronatine. J Bacteriol 1998, 180:1360-1367.

31. Keane PJ, Kerr A, New PB: Crown gall of stone fruit. II. Identification and nomenclature of Agrobacterium isolates. Aus J Biol Sci 1970, 23:585-595.

32. Scalera SE, Ward OG: A quantitative study of ethyl methanesulfonateinduced alkylation of Vicia faba DNA. Mutat Res 1971, 12:71-79.

33. Thomas MD, Leary JV: Mutagenicity and pathogenicity in Pseudomonas syringae pv. glycinea (Pseudomonas glycinea). J Gen Microbiol 1980, 121:349-355.

34. Canfield ML, Baca S, Moore LW: Isolation of Pseudomonas syringae from 40 cultivars of diseased woody plants with tip dieback in Pacific Northwest nurseries. Plant Dis 1986, 70:647-650.

35. Sawada H, Kanaya S, Tsuda M, Saitous N: Phylogenetic analysis of Pseudomonas syringae pathovars suggests that horizontal transfer of $\operatorname{argK}$ and the evolutionary stability of the hrp gene cluster. J Mol Evol 1999, 49:627-644.

36. Tamura K, Dudley J, Nei M, Kumar S: MEGA4: molecular evolutionary genetic analysis (MEGA) software version 4.0. Mol Biol Evol 2007, 24:1596-1599.

doi:10.1186/2041-2223-5-10

Cite this article as: James et al.: Evaluating the impacts of stressors of Pseudomonas syringae pathovar tomato on the effectiveness of multi-locus variable number tandem repeat analysis and multi-locus sequence typing in microbial forensic investigations. Investigative Genetics 2014 5:10.

\section{Submit your next manuscript to BioMed Central and take full advantage of:}

- Convenient online submission

- Thorough peer review

- No space constraints or color figure charges

- Immediate publication on acceptance

- Inclusion in PubMed, CAS, Scopus and Google Scholar

- Research which is freely available for redistribution 